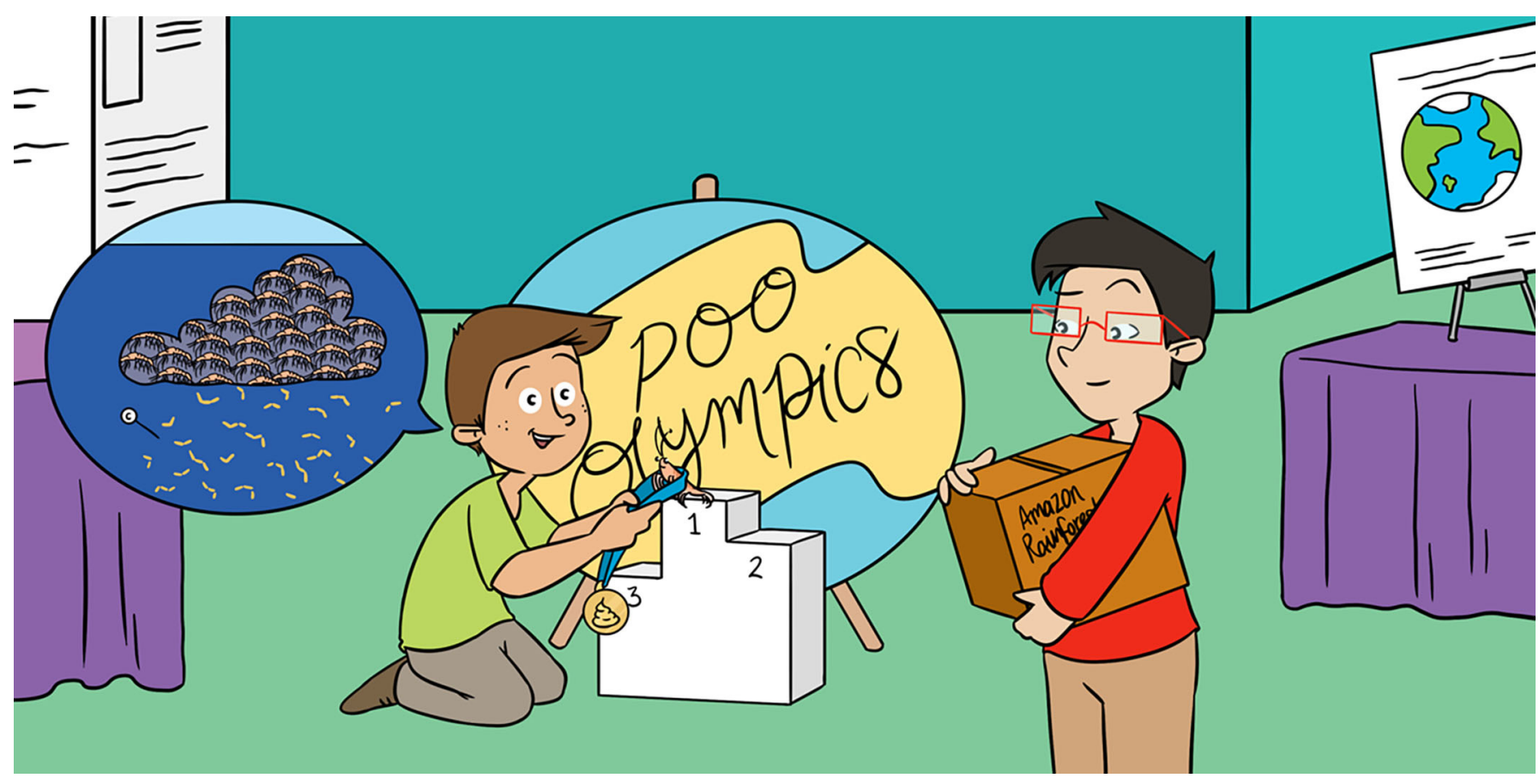

\title{
WHY KRILL SWARMS ARE IMPORTANT TO THE GLOBAL CLIMATE
}

\author{
Anna Belcher ${ }^{1 *}$, Emma L. Cavan ${ }^{2}$ and Geraint A. Tarling ${ }^{1}$ \\ ${ }^{1}$ Ecosystems Team, British Antarctic Survey, Cambridge, United Kingdom \\ ${ }^{2}$ Department of Life Sciences, Imperial College London, Silwood Park Campus, London, United Kingdom
}

\section{YOUNG REVIEWERS:}

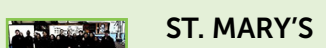

$-12-1$ (I) HIGH SCHOOL

AGE: 14
Ocean life helps keep atmospheric levels of carbon dioxide lower by taking carbon out of the atmosphere and transporting it to the deep ocean, through sinking particles. Antarctic krill live in the Southern Ocean and gather in huge swarms. Importantly, they produce large, fast-sinking poo (called fecal strings), meaning that we get a rain of poo below these swarms, which takes carbon quickly to the deep ocean. We calculate how krill lower the amount of carbon in the atmosphere by estimating how many krill there are and how many fecal strings each produces. These calculations reveal that Antarctic krill living near sea ice remove 39 million tons of carbon from the surface ocean each year. That is about the same weight as 100 million polar bears! Krill are therefore not only important food for whales and penguins, but also vital engineers of our climate and so they require protection. 
PHYTOPLANKTON

Microscopic

plant-like algae.

\section{ZOOPLANKTON}

Animals that only have weak swimming movements so drift with the ocean/wind driven currents.

\section{FECAL STRING}

The type of poo produced by animals like Antarctic krill, containing lots of partly digested food inside a tubular membrane, often rich in carbon.

\section{ANTARCTIC KRILL}

Swimming crustaceans that live in the waters that surround Antarctica.

\section{A BIOLOGICAL SPONGE FOR CARBON}

Our oceans are not only a fantastic playground where we can enjoy swimming and all sorts of fun activities, but they also play an important role in our climate. Full of amazing life, the tiny plants (phytoplankton) of the ocean are to thank for the oxygen in every other breath we take! In fact, without ocean life, levels of carbon dioxide would be about 50\% higher than they are today [1]. Just like trees on land, phytoplankton in the ocean take up carbon dioxide and use sunlight to make the food they need to survive. In doing this, carbon gets locked up in the plant cells, which in turn are fed upon by marine animals, such as zooplankton and krill. Like all animals on land, marine animals do not use all the food they eat, and what they do not use, they pass out again as poo! Their poos (called fecal strings) are like tiny torpedoes packed with carbon, and as they sink through the ocean they take that carbon with them, locking it away from the atmosphere. Great news for reducing the carbon dioxide in our atmosphere!

Unfortunately, there are a whole bunch of animals living in the deep ocean looking for tasty snacks that rain down from above. The fecal strings from the krill, as well as dead marine plant and animal remains, sink through the ocean and most get gobbled up by the animals along the way. This means that only about $1 \%$ of sinking particles makes it all the way to the seabed. Once at the seabed, the carbon in these particles can be buried and locked away for millions of years in sediments and rocks. The more carbon we can get to the sediments, the less is in the atmosphere, which is great for our climate! The faster a particle sinks, the less time there is for it to end up on the dinner plate of a deep-ocean animal, so the more of its carbon reaches the seabed. It turns out that not all animals are created equal when it comes to the sinking speed of their poo!

\section{KRILL POO: THE OLYMPIC SINKING CHAMPIONS}

Antarctic krill are swimming crustaceans (part of the same family of animals as crabs, lobsters, and prawns) that can grow up to about $7 \mathrm{~cm}$ in length and can live for up to 5-6 years in the wild (Figure 1A). They are only found in the Southern Ocean, the large expanse of ocean surrounding Antarctica. Krill are powerful swimmers and can swim against some of the strongest ocean flows in the world. In fact, krill never stop swimming their whole lives. This takes an incredible amount of energy, which they have to fuel by eating up to $10 \%$ of their body weight daily. That would be equivalent to us eating 12 full meals per day. However, rather than burgers and chips, krill food is mainly plant-based, particularly a type of phytoplankton called diatoms, which are full of energy and nutritional fats.

All that eating produces a lot of poo. One of the amazing things about krill is that their poo is produced in long chains called fecal 
Figure 1

\section{(A) An}

Antarctic krill (total length from eye to tail, $60 \mathrm{~mm}$ ). (B) The sinking champion: krill poo. Krill fecal strings are compact, and their streamline shape means they can sink quickly through the ocean. They often form these long chains as shown. (C) One of the traps used to catch sinking poo.

\section{BLOOM}

A region of the ocean where there is a high concentration of marine plants caused by rapid reproduction.

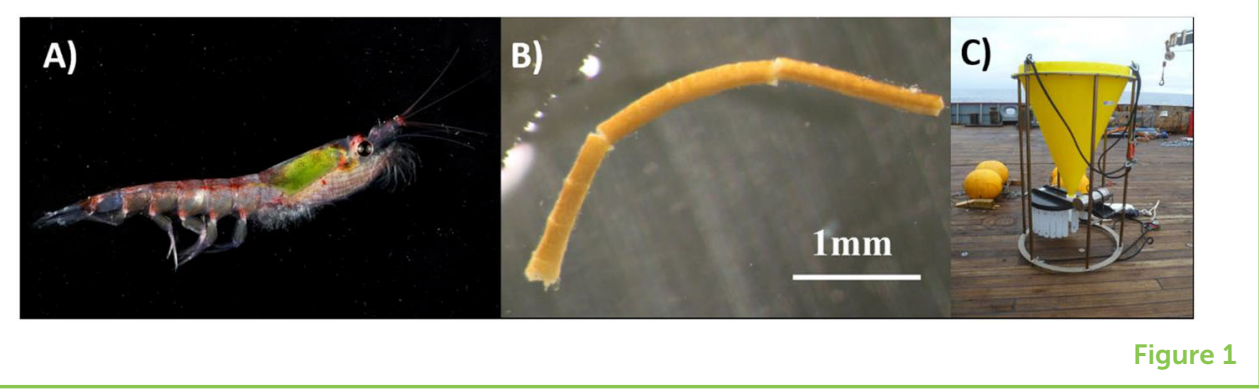

strings (Figure 1B), which can sink quickly through the ocean at rates of hundreds of meters a day. Not quite Olympic sprinting speed, but they would win a medal in any poo-sinking race. In some parts of the Southern Ocean, we find lots of krill fecal strings in the collection traps that we leave out in the ocean. We deploy these traps on a long line that is usually anchored to the sea bed. The trap is essentially a big funnel that catches all the particles that are sinking down and collects them in sample cups at the bottom (Figure 1C). Sometimes the samples can be full of krill fecal strings and not much else, which we think is because there has been many millions of krill in the area swimming above the trap, in a large group called a swarm.

\section{KRILL SWARMS: BIG IS BEAUTIFUL}

One of the fascinating things about krill, which makes them even better at transferring carbon to the deep ocean, is that they hang out with millions of their friends in swarms. Some of these swarms are huge and can extend over areas of about $100 \mathrm{~km}^{2}$ [2], which is about the same size as the island of Jersey off the UK. Krill much prefer being in a swarm than swimming separately, and it seems the bigger the swarm, the better. About $90 \%$ of all krill that live in the Southern Ocean hang out in a relatively small number of big swarms [3]. Being in a swarm offers protection from the many krill-eating predators, such as penguins, seals, and whales. It is also a better way to find the big patches (blooms) of their phytoplankton food that are scattered far and wide in the ocean; many pairs of eyes (and antennae) are better than one. These rare but huge swarms are really important, not only for the Southern Ocean wildlife that feed on them, but also for transferring carbon to the deep ocean, as lots of krill means lots of sinking poo!

\section{THE KRILL CARBON HIGHWAY}

Large krill swarms swim through the oceans, feeding on any blooms of phytoplankton that cross their paths. The sheer number of krill in these swarms means that, during this feeding frenzy, we get huge numbers of fecal strings that rain down below the swarm The huge number of fecal strings means that there is no way the poo-eating animals (such 


\section{Figure 2}

The krill poo carbon highway.

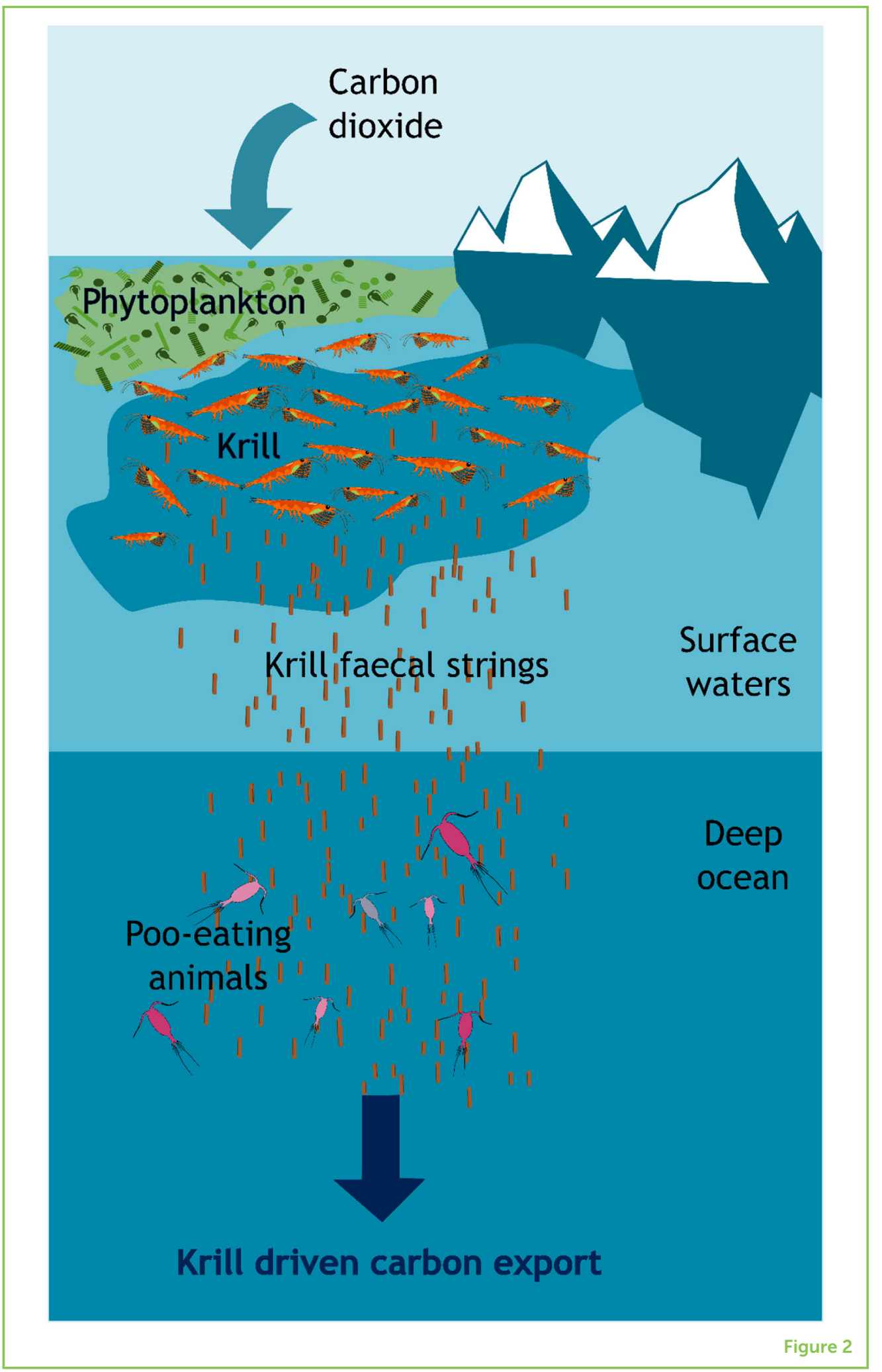

as fish and zooplankton) below can keep up with the supply-it is like being at a sushi bar and trying to eat huge platefuls of food as they come along at many times the normal speed! As these poo-eaters are overwhelmed, most of the fecal strings avoid being eaten and sink into the deep ocean, taking their carbon with them (Figure 2). 
MARGINAL ICE

\section{ZONE (MIZ)}

The transition zone between the pack-ice and the open sea, where there are varying amounts of ice and open water.

Lots of carbon can make it to the deep ocean when swarms of krill feed on phytoplankton near the surface, producing huge numbers of rapidly sinking fecal strings. There can be so many fecal strings that they cannot all be captured by the poo-eating animals living deeper in the ocean. This means lots of them can make it to the deep ocean, taking with them lots of carbon.

As these krill swarms are so few and far between, it is really difficult to capture these rare rain events, but we think they could transfer a lot of carbon to the deep ocean [4]. We wanted to find a way to estimate how many fecal strings are produced so that we could predict how much carbon they transfer out of the surface ocean. We particularly zoned in on a region of the Southern Ocean called the marginal ice zone (MIZ) The MIZ is where sea-ice starts to open up into the open ocean. We focused on the MIZ because conditions there are perfect for the generation of fast-sinking poo, since there are both lots of phytoplankton blooms and large numbers of krill. The location of the MIZ varies over seasons as the ice extent grows in the winter and melts back in the summer. As part of our calculation, we used satellite images to work out the size of the MIZ over the course of a typical year (Figure 3).

The next stage was to determine how many krill live in the MIZ. There have been many measurements of krill numbers in the Southern Ocean over the past decade, mainly using nets towed behind ships [5]. We put together all available records of net catches made in MIZ regions and estimated the numbers of krill in these regions over the course of a typical year.

The final part of the calculation was to work out how many fecal strings an average krill produces. We used information from a number of different science teams who fed captive krill and then measured the amount, size, and sinking speed of the fecal strings they produced [6].

Through putting these pieces of evidence together, we were able to estimate just how many fecal strings successfully make it out of the surface ocean and, more importantly, how much carbon they take with them. Our best estimate is that Antarctic krill living in the MIZ transport 39 million tons of carbon per year into the deep ocean through their poo. This is a minimum estimate, since many krill live in other areas beyond the MIZ. Nevertheless, this minimum estimate suggests that Antarctic krill transfer as much carbon in their poo as all of the carbon presently emitted from all the cars, buses, trains and even planes flying within the UK! Therefore, these social, hungry, phytoplankton eaters are also important climate engineers through doing what they must do every day-taking a poo. 


\section{Figure 3}

Steps in the model to estimate the number of krill fecal strings that make it successfully out of the surface ocean and take carbon to the deep sea. This keeps it out of the atmosphere! The map on the left shows where we find high (red) and low (green) numbers of krill in the marginal ice zone around Antarctica.

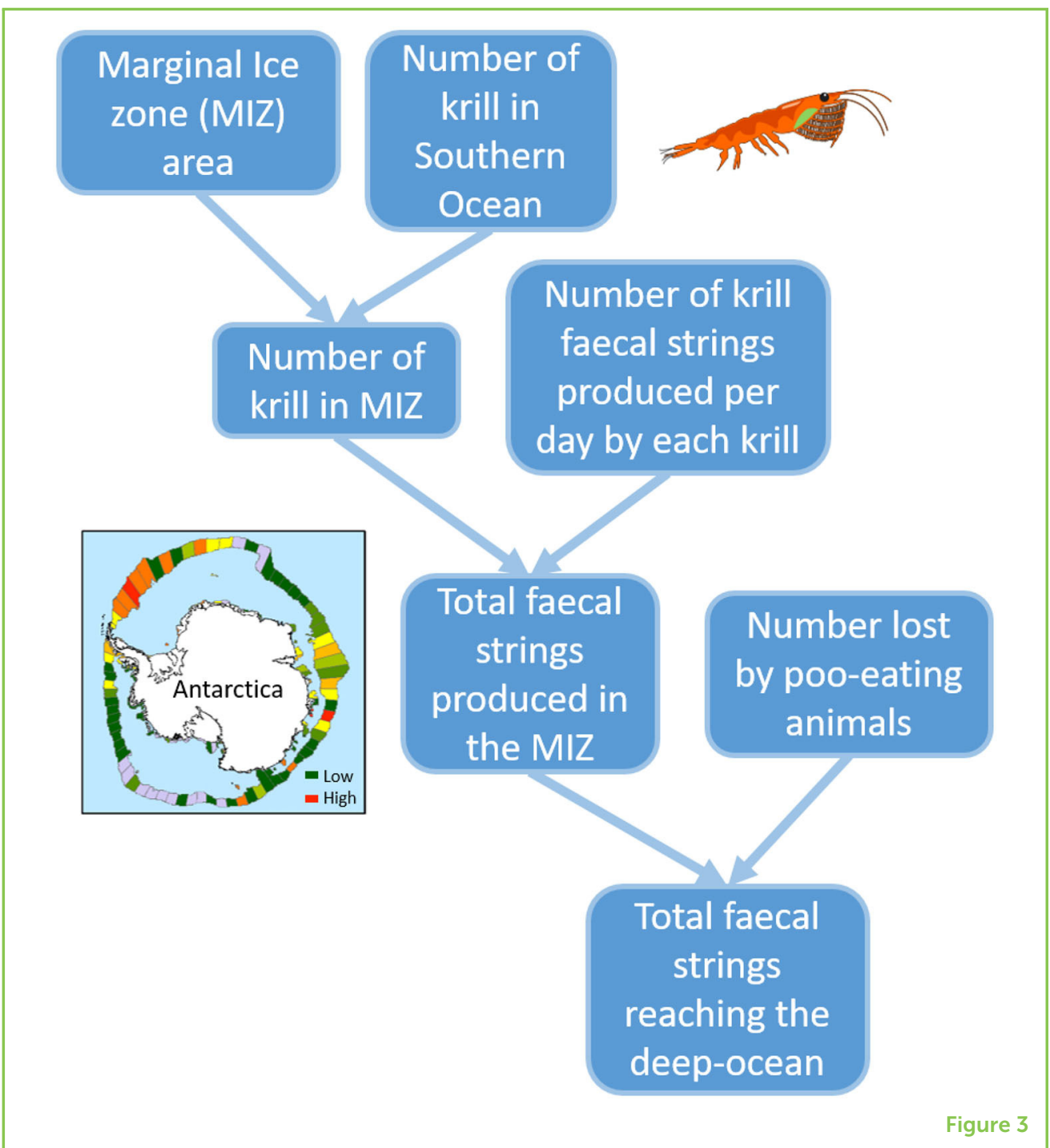

\section{KRILL AND OUR CLIMATE}

Once a poo, from krill or any other animal or fish, makes it to the deep ocean it will stay there for 10,100, or even 1,000 years! This is really important for the climate, as it means carbon is locked in the deep ocean and cannot return to the atmosphere as carbon dioxide, which is what is causing the planet to warm so quickly. It can be hard to study animals in the ocean, and we are only just learning how important their poo is. So, we need to be careful about what we take from the ocean and the impact we have on ocean communities, not only because krill are important food for many animals, but also because their poo may be important for the climate! However, next time you are in a storm, be grateful that it is only water that is falling on your head!

\section{ACKNOWLEDGMENTS}

We would like to thank our young reader, Arwen Tarling, for a critical review of this manuscript. 


\section{ORIGINAL SOURCE ARTICLE}

Belcher, A., Henson, S. A., Manno, C., Hill, S. L., Atkinson, A., Thorpe, S. E., et al. 2019. Krill faecal pellets drive hidden pulses of particulate organic carbon in the marginal ice zone. Nat. Commun. 10:889. doi: 10.1038/s41467-019-08847-1

\section{REFERENCES}

1. Parekh, P., Dutkiewicz, S., Follows, M. J., and Ito, T. 2006. Atmospheric carbon dioxide in a less dusty world. Geophys. Res. Lett. 33:L03610. doi: 10.1029/2005GL025098

2. Tarling, G. A., and Fielding, S. 2016. "Swarming and behaviour in Antarctic krill," in Biology and Ecology of Antarctic Krill, ed V. Siegel (Cham: Springer). p. 279-319. doi: 10.1007/978-3-319-29279-3_8

3. Tarling, G. A., Klevjer, T., Fielding, S., Watkins, J., Atkinson, A., Murphy, E., et al. 2009. Variability and predictability of Antarctic krill swarm structure. Deep Sea Res. Part / 56:1994-2012. doi: 10.1016/j.dsr.2009.07.004

4. Belcher, A., Henson, S. A., Manno, C., Hill, S. L., Atkinson, A., Thorpe, S. E., et al. 2019. Krill faecal pellets drive hidden pulses of particulate organic carbon in the marginal ice zone. Nat. Commun. 10:889. doi: 10.1038/s41467-019-08847-1

5. Atkinson, A., Hill, S. L., Pakhomov, E. A., Siegel, V., Reiss, C. S., Loeb, V. J., et al. 2019. Krill (Euphausia superba) distribution contracts southward during rapid regional warming. Nat. Clim. Change 9:142-7. doi: 10.1038/s41558-018-0370-z

6. Clarke, A., Quetin, L. B., and Ross, R. M. 1988. Laboratory and field estimates of the rate of faecal pellet production by Antarctic krill, Euphausia superba. Mar. Biol. 98:557-63. doi: 10.1007/BF00391547

SUBMITTED: 10 December 2019; ACCEPTED: 01 September 2020; PUBLISHED ONLINE: 19 October 2020.

EDITED BY: Laura Lorenzoni, National Aeronautics and Space Administration (NASA), United States

CITATION: Belcher A, Cavan EL and Tarling GA (2020) Why Krill Swarms Are Important to the Global Climate. Front. Young Minds 8:518995. doi: 10.3389/frym. 2020.518995

CONFLICT OF INTEREST: The authors declare that the research was conducted in the absence of any commercial or financial relationships that could be construed as a potential conflict of interest.

COPYRIGHT () 2020 Belcher, Cavan and Tarling. This is an open-access article distributed under the terms of the Creative Commons Attribution License (CC BY). The use, distribution or reproduction in other forums is permitted, provided the original author(s) and the copyright owner(s) are credited and that the original publication in this journal is cited, in accordance with accepted academic practice. No use, distribution or reproduction is permitted which does not comply with these terms. 


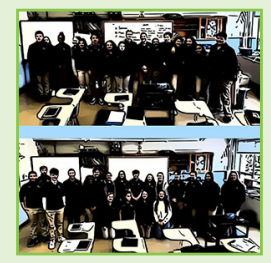

\section{YOUNG REVIEWERS}

\section{ST. MARY'S HIGH SCHOOL, AGE: 14}

St. Mary's is a Catholic, college-preparatory school developing students in grades 6-12 from more than 30 communities on Boston's North Shore. Shaping authentic men and women of talent and faith. The Honors Biology course focuses on developing scientific inquiry skills that can be applied throughout the students' academic experiences. It has been an incredible experience for our students to get direct experience in the peer-review process and we are so excited to see the final product.

\section{AUTHORS}
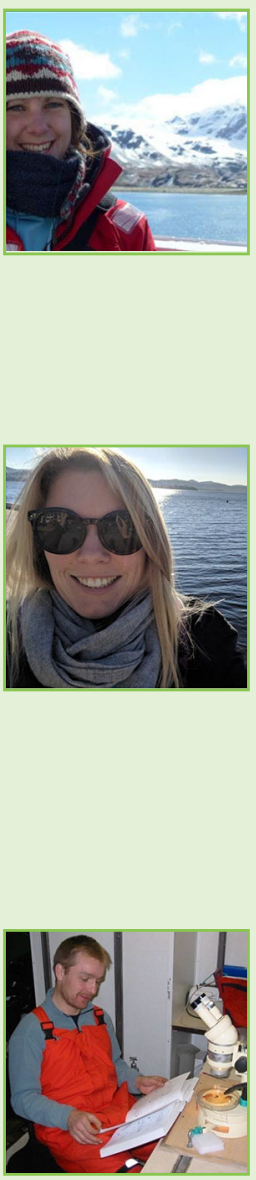

\section{ANNA BELCHER}

I am a marine scientist at the British Antarctic Survey in Cambridge, UK. I am really interested in how ocean life is involved in the global carbon cycle and how it helps remove carbon dioxide from the atmosphere. In particular, I study Antarctic krill, fish living in the dark ocean, and the importance of the food that copepods eat for their overwintering at depth. When I am not in the office or out at sea collecting data, I spend my time rock climbing, bike-packing, and enjoying the wild outdoors. *annbelabas.ac.uk

\section{EMMA L. CAVAN}

I research how animals and plants living in the sea and rivers interact with the environment. I now work at Imperial College London, having worked at the University of Tasmania (Australia) for 2 years. My first research as a Ph.D. student was on the importance of plankton poo in the ocean carbon cycle and so I am often known as Dr. Plankton Poo! My main scientific interest is how climate change will impact our environment and the health of our oceans. In my spare time I enjoy finding any excuse to get to the UK coast, stopping my dog from chasing birds, relaxing on the sofa, and a good old-fashioned English pub!

\section{GERAINT A. TARLING}

I am a biological oceanographer at the British Antarctic survey. I work at both poles, surveying the range of animals inhabiting the sunlit and twilight oceanic zones. These organisms range from microscopic zooplankton to deep-dwelling fish, also encompassing gelatinous organisms, krill, and pteropods (sea-butterflies). I am particularly interested in how they behave, most notably their daily migrations from ocean depths to the sea surface. I am also interested in how much carbon these communities move from the upper to the deeper parts of the ocean and how effective this process is in compensating for human emissions of $\mathrm{CO}_{2}$. When on long, polar voyages, I pass my spare time playing the accordion and spotting wildlife. 